\title{
Happiness and Memory: Affective Significance of Endowment and Contrast
}

\author{
Varda Liberman \\ The Interdisciplinary Center Herzliya, Israel
}

\author{
Julia K. Boehm and Sonja Lyubomirsky \\ University of California, Riverside
}

\author{
Lee D. Ross \\ Stanford University
}

\begin{abstract}
Three studies (two conducted in Israel and one in the United States) examined associations between self-rated dispositional happiness and tendencies to treat memories of positive and negative events as sources of enhanced or attenuated happiness through the use of "endowment" and "contrast." Although participants generally endorsed items describing happiness-enhancing tendencies more than happinessdiminishing ones, self-reported happiness was associated with greater endorsement of "positive endowment" items and less endorsement of "negative endowment" items, and also with less endorsement of items that involved contrasting the present with happier times in the past. Only in the American sample, however, was happiness associated with greater endorsement of items that involved contrasting the present with less happy times in the past. These data suggest that relatively unhappy people show somewhat conflicting memorial tendencies vis-à-vis happiness, whereas very happy people show simpler, and less conflicting, tendencies. These findings augment the existing literatures on the affective consequences of memory, which have been concerned more with mood than with temperament and/or have dealt only with a subset of the endowment and contrast tendencies explored in the present work.
\end{abstract}

Keywords: endowment, contrast, happiness, memory

\author{
"Although we don't live in the past, we live with the past." \\ -Rabbi Mark Miller \\ "Good memories are our second chance at happiness." \\ -Queen Elizabeth II \\ "We'll always have Paris." \\ -Humphrey Bogart (as Rick Blaine) to Ingrid Bergman (as Ilsa Lund) \\ in Casablanca
}

Life inevitably offers a mixture of good and bad times, triumphs and defeats, periods of bliss and periods of sadness, loss, or even humiliation. With the passage of time, such experiences remain with us as memories - memories that can play an important role in determining both our immediate and enduring happiness and sense of well-being. The present research examines two perspectives that

Varda Liberman, Business School, The Interdisciplinary Center Herzliya, Israel; Julia K. Boehm and Sonja Lyubomirsky, Department of Psychology, University of California, Riverside, Riverside, California; Lee D. Ross, Department of Psychology, Stanford University, Stanford, California.

This research was supported by an Academic Senate intramural grant from the University of California, Riverside. We thank Rene Dickerhoof for her generous assistance with statistical analyses.

Correspondence concerning this article should be addressed to Varda Liberman, The Interdisciplinary Center Herzliya, P. O. Box 167 Herzliya 46150, Israel. E-mail: liberman@idc.ac.il can mediate the effect of positive and negative past experiences. These perspectives regarding past events, using language suggested by Tversky and Griffin (1991), can be termed endowment and contrast. ${ }^{1}$

Endowment effects are direct products of the valence of the events and memories in question. Positive experiences, great and small - the stirrings of love, the birth of a child, the achievement of a long strived-for goal, or even a memorable meal or perfect sunset-increase one's memorial capital and constitute a kind of affective endowment that can enhance one's happiness. Conversely, negative experiences-illnesses, privations, romantic disappointments, lost opportunities, and even petty insults endureddiminish such capital, and exert a negative impact on one's memorial endowment in a way that can limit one's happiness Contrast effects, as the name suggests, are of the opposite sort.

\footnotetext{
${ }^{1}$ What we have termed endowment and contrast effects have also been explored in the context of social and self-judgment, with the term assimilation used in place of endowment. Research suggests that assimilation and contrast yield different self-judgments, especially when such selfjudgments are based on a comparison with another person (Markman \& McMullen, 2003; Mussweiler, 2003; Schwarz \& Bless, 1992). There is also the suggestion that people may consider an earlier version of the self as a standard of comparison. Although the connection between these conceptions and phenomena and those discussed in the present research is somewhat remote, in both cases assimilation effects are thought to represent a direct relationship between the standard and the judgment, whereas contrast effects are thought to represent an opposite relationship between the standard and the judgment (Schwarz \& Bless, 1992).
} 
Contrasting the present with positive times experienced in the past can make one feel less happy and diminish one's sense of wellbeing, whereas contrasting the present with negative times experienced in the past can make one feel happier (or at least less unhappy) and enhance one's sense of well-being.

The focus of the present research is the hypothesis that dispositional happiness is associated with the tendency to endow positive past events but not negative ones, and to contrast the present with worse times in the past but not with better ones. It has long been recognized that happy individuals' immediate responses to events are apt to be more positive (in the case of positive events) or less negative (in the case of negative events) than those of unhappy individuals. Not only does such evidence come from a variety of correlational studies (Lyubomirsky \& Tucker, 1998; Lyubomirsky, Tucker, \& Kasri, 2001; Seidlitz \& Diener, 1993; Stones \& Kozma, 1986), but the very term happy when applied to an individual connotes a tendency to find joy in positive everyday events, and to show resilience, and a degree of equanimity if not cheerfulness, in the face of adversity. The association of present happiness and optimism about the future is also well established in numerous studies of personality (DeNeve \& Cooper, 1998; Diener, Suh, Lucas, \& Smith, 1999; Lucas, Diener, \& Suh, 1996; Lyubomirsky, Tkach, \& DiMatteo, 2006).

What we suggest here is a similar relationship between happiness and ways of dealing not with events themselves, but with memories, positive and negative, regarding those past events-a relationship that we contend is critical to our understanding of happiness itself. As our opening quotes from Rabbi Miller and Queen Elizabeth suggest, "we all live with the past," and memories of the past give us a "second chance at happiness" (and presumably a second chance at sadness as well). The three studies we report were designed to provide us with a keener understanding of the various ways, some obvious and some not-so-obvious, in which contemplating the past can contribute to chronic happiness or sadness. Specifically, we hope to show why, in everyday experience, we so often see people who manifest everyday happiness and joie de vivre in the face of histories of daunting losses and adversity, and other people who manifest chronic sadness and regret in the face of histories of good fortune and privilege.

\section{Past Research on Happiness and Reflections on the Past}

Previous researchers have recognized that, over and above having positive experiences, the ability or tendency to "savor" or continue to elicit positive feelings from such experiences can enhance the intensity and frequency of individuals' current happiness (Bryant, 1989; Bryant \& Veroff, 2006; Lyubomirsky \& Tucker, 1998). Additional evidence comes from research on "capitalization," or the explicit and overt sharing of positive events with others, which suggests that such sharing can increase positive emotions (Langston, 1994) and even longer-term well-being (Gable, Reis, Impett, \& Asher, 2004).

Conversely, there is also evidence that sustained attention to, or "rumination" about, past negative experiences can contribute to present unhappiness (Nolen-Hoeksema, 1991). Indeed, the tendency to ruminate has been linked to a variety of detrimental consequences, including prolonged depression (Nolen-Hoeksema, Parker, \& Larson, 1994), negatively biased attitudes (Lyubomirsky \& Nolen-Hoeksema, 1995), impaired concentration (Lyubomir- sky, Kasri, \& Zehm, 2003), and poor problem-solving skills (Lyubomirsky \& Nolen-Hoeksema, 1995). While the term rumination connotes not just memory of a negative event but sustained, recursive thinking about that event, it essentially refers to a negative endowment effect.

Evidence from several literatures, however, also attests to the fact that consideration of past negative life events can sometimes have positive consequences. In a well-known study, Taylor, Wood, and Lichtman (1983) found that experiences of victimization can allow one to gain knowledge about oneself, to find new meaning in life, or to reappraise one's priorities. Collins, Taylor, and Skokan (1990) later found that acknowledgment of these positive consequences can enhance the relevant "benefits." In the domain of health psychology, there is also evidence that people with chronic pain report at least temporary improvements in their moods when they are able to remind themselves of the benefits stemming from their conditions, even when their actual pain is extreme (Affleck \& Tennen, 1996).

More pertinent to the present issue of contrast is the finding of increased pleasant mood and decreased unpleasant mood when chronic pain sufferers were asked to remember a time in the past when they were worse off than the present (Affleck, Tennen, Urrows, Higgins, \& Abeles, 2000). Mood enhancement through a contrast-inducing manipulation has also been demonstrated in a clever study in which participants were presented with a "realistic" (i.e., appalling) versus a more idealized description of living conditions at the start of the 20th century (Dermer, Cohen, Jacobsen, $\&$ Anderson, 1979). Participants hearing the realistic description of the relevant living conditions reported greater satisfaction with their own lives than those hearing the more idealized description. Finally, it is worth noting that one of the items that distinguished peer-nominated happy individuals from unhappy ones in Lyubomirsky and Tucker's (1998) correlational study of coping strategies involved a contrast between a negative past event and the present. The item read: "When reminded of the (negative) event, I thought about how much better things are now."

Few researchers have sought to induce unhappiness through contrast strategies. But the capacity of reflections about happier times to produce sadness cannot be doubted by any reader who fondly recalls the days before the loss of a loved one, the lapsing of a once-close friendship, or the reduction of one's physical capacities. The results of Brickman, Coates, and Janoff-Bulman's (1978) oft-cited study of lottery winners and accident victims, which are usually interpreted in terms of adaptation and cognitive salience, may be interpreted in terms of contrast effects as well. That is, the small pleasures and disappointments of everyday life may contrast negatively with the earlier thrill of winning the lottery, or they may contrast positively with the earlier trauma of the accident and its immediate aftermath.

\section{Hypothesized Associations Between Happiness and Use of Endowment and Contrast}

Whereas past research has demonstrated the capacity of both positive and negative events to have either positive or negative consequences for future happiness and well-being, the focus of the present research is on the association between chronic or dispositional happiness and the specific positive and negative endowment and contrast tendencies that can give rise to and/or perpetuate such 
happiness. The conceptual analysis offered by Tversky and Griffin (1991) on endowment and contrast effects suggests the possibility that the tendency to endow past positive life events-that is, to savor and acquire joy from retrospectively thinking about these experiences - might be associated with relatively higher levels of self-reported happiness. Conversely, that analysis (and considerable past data on the correlates of dysphoria) suggests that the tendency to endow past negative life events - that is, to dwell on the negative thoughts and feelings involved in contemplating these experiences - might be associated with relatively lower levels of self-reported happiness. In the case of contrast effects, the Tversky and Griffin analysis suggests that the tendency to contrast the present with particularly positive past life events might be associated with relatively lower levels of self-reported happiness, whereas the tendency to contrast the present with negative past life events might be associated with relatively greater happiness.

Our research addressed these predictions in three separate correlational studies-two conducted in Israel, with questionnaire items in Hebrew, and one in the United States, with items in English. In each study, participants rated their happiness and answered questions about how they tend to think about past positive and negative events, with a focus on possible endowment and contrast effects. In Study 1, the questionnaire items pertained to past positive and negative events "in general"; in Studies 2 and 3 , they pertained to specific events associated with particular periods in the respondents' lives.

In reporting the results of these three studies, we test the predicted associations between self-reported happiness and the specified endowment and contrast tendencies (with an emphasis not on individual questionnaire items but on composite measures) by calculating simple correlation coefficients. In all three studies, however, we also provide mean responses for participants in the highest, middle, and lowest thirds of the happiness distribution (i.e., the very happy, moderately happy, and unhappy). In so doing, we seek to give the reader a sense not only of the relevant between-groups differences reflected in the reported correlations, but also of the absolute levels of endorsement of the various types of endowment and contrast items.

\section{Study 1}

\section{Method}

\section{Participants}

A total of 97 undergraduate students (69 men and 28 women, all Jewish) completed a questionnaire containing happiness measures and items regarding the consequences of memory. Participants were enrolled in a business school class at the Interdisciplinary Center in Herzliya. ${ }^{2}$ Ages of the participants ranged from 21 to 35 years $(M=24.6)$. They received course credit but no monetary payment for their participation.

\section{Procedure}

Students received the questionnaire (with all items presented in Hebrew) as an e-mail attachment and were invited to return it when completed via e-mail attachment to receive the relevant course credit. Participants were informed that the questionnaire dealt with "memories and feelings" and was part of a joint study being conducted both in Israel and the United States. Following some demographic questions (e.g., age, gender, etc.) were 35 items relevant to endowment and contrast perspectives, each consisting of a statement about memories of events in participants' lives when they were younger. Participants responded by indicating how much each statement applied to them. The next items asked participants to specify and briefly describe "one of the happiest events they had experienced" and "one of the unhappiest events they had experienced," and then to indicate how often they find themselves thinking about each experience today. Finally, participants completed measures of happiness, life satisfaction, and optimism.

\section{Measures}

Endowment and contrast items. The questionnaire items of primary interest pertained to the participants' use of endowment and contrast when considering past positive and negative life experiences "in general." All endowment and contrast items were presented in the form of statements that were originally written in Hebrew, but then back-translated into English so that the coauthors could jointly assure the appropriateness of the relevant wordings. All of the endowment items, including both the four positive or happiness-enhancing endowment (PE) items and the five negative or happiness-diminishing endowment (NE) items are presented in Table 1. All of the contrast items, including the four positive or happiness-enhancing contrast items (PC) and the three negative or happiness-diminishing contrast (NC) items, are presented in Table 2. Preliminary analysis revealed that the four PE items yielded a Cronbach's alpha of .71, whereas the five NE items yielded an alpha of .77. The four PC items and three NC items yielded alpha coefficients of .55 and .77, respectively.

These 16 items were embedded among 19 items that were irrelevant to endowment or contrast perspectives but that nevertheless were pertinent to affect and/or memory (e.g., "When something makes me happy, it is usually a result of careful planning and hard work" and "I think mainly about the present instead of worrying about the future"). Where instructive, we shall report responses to some of these "filler" items as well. Responses to all items (i.e., endowment and contrast items and filler items alike) were made on 7-point scales anchored at 1 (not at all true of me), and 7 (completely true of me), with a midpoint of 4 (somewhat true of me).

Happiness. To assess self-rated happiness, we used the fouritem Subjective Happiness Scale (SHS; Lyubomirsky \& Lepper, 1999) translated into Hebrew. ${ }^{3}$ The SHS includes a pair of items

\footnotetext{
${ }^{2}$ Although undergraduates, the Israeli students in Studies 1 and 2 (having previously completed 3 years of military service in the case of men and 2 years in the case of women) were older than their American counterparts in Study 3. The Israeli participants, furthermore, were enrolled in programs offering preprofessional training in business or computer science whereas the Americans were generally pursuing a liberal arts curriculum.

3 The SHS has demonstrated high internal consistency (Cronbach's $\alpha$ s range from .79 to .94 across 14 different studies) and high test-retest stability (Pearson's $r=.90$ for 4 weeks and .71 for 3 months). It has also been shown to converge with other measures of well-being; for example, when correlated with the Satisfaction With Life Scale (SWLS; Diener et al., 1985) rs range from .61 to .72. Moreover, the SHS strongly correlates with informant ratings of happiness $(r=0.54)$. For more detailed information on the characteristics of this measure, see Lyubomirsky and Lepper (1999).
} 
Table 1

Positive Endowment (PE) and Negative Endowment (NE) Items, Mean Endorsement Levels by Subjective Happiness Scale (SHS) Groups, and Correlations Between SHS and Level of Endorsement (Study 1)

\begin{tabular}{|c|c|c|c|c|}
\hline Items & Very happy & Moderately happy & Unhappy & $r$ \\
\hline When I think about happy events in the past, I often smile or laugh. (PE) & 5.83 & 5.43 & 4.93 & $.32^{* * * *}$ \\
\hline Happy memories of the past help me when I am feeling a little depressed. (PE) & 4.80 & 4.13 & 4.33 & .14 \\
\hline Thinking about good times in the past continues to make me happy today. (PE) & 5.13 & 4.95 & 4.41 & $.23^{*}$ \\
\hline When I recall happy events in the past, I realize how much they enrich my life. (PE) & 5.67 & 5.20 & 5.26 & $.23^{*}$ \\
\hline PE composite & 5.36 & 4.93 & 4.73 & $.31^{* * *}$ \\
\hline Failures I experienced in the past still hurt today. (NE) & 2.53 & 2.80 & 2.93 & $-.24^{*}$ \\
\hline Unhappy events in the past continue to make me unhappy even today. (NE) & 2.10 & 2.65 & 2.96 & $-.31^{* * *}$ \\
\hline $\begin{array}{l}\text { When I recall unhappy events in the past, I realize what a negative effect they had } \\
\text { on my life. (NE) }\end{array}$ & 2.10 & 2.78 & 3.00 & $-.30^{\text {*** }}$ \\
\hline $\begin{array}{l}\text { I sometimes dwell on unhappy past events and even relive them in a way that } \\
\text { makes me feel sad and depressed. (NE) }\end{array}$ & 1.73 & 2.60 & 3.04 & $-.37^{* * * *}$ \\
\hline When I recall unhappy events in the past, I feel sorry for myself. (NE) & 2.40 & 2.20 & 3.15 & $-.29^{* *}$ \\
\hline NE composite & 2.17 & 2.61 & 3.00 & $-.42^{* * * *}$ \\
\hline
\end{tabular}

${ }^{*} p<.05 . \quad{ }^{* *} p<.01 . \quad{ }^{* * *} p<.001$.

that first ask respondents to characterize themselves on a 7-point scale $(1=$ I consider myself a very unhappy person, $7=$ I consider myself a very happy person) and then to rate themselves relative to their peers on another 7-point scale $(1=$ less happy, $7=$ more happy). The other two items ask participants to respond to an additional pair of self-description statements. One statement reads: "Some people are generally very happy. They enjoy life regardless of what is going on, getting the most out of everything. To what extent does this characterization describe you?" The other statement (for which responses were reversed coded) reads: "Some people are generally not very happy. Although they are not depressed, they never seem as happy as they might be. To what extent does this characterization describe you?" Responses to these last two items were also made on a 7 -point scale $(1=$ not at all, $7=a$ great deal). The internal consistency of the SHS in the current study was .60. As noted earlier, although we examine the relationships between these self-ratings and scores on the relevant endowment and contrast scales using correlation coefficients, we also provide means on each scale for respondents whom we classified as very happy $(n=30)$, moderately happy $(n=40)$, and unhappy $(n=27)$ based on a rough trichotomy of these SHS scores. $^{4,5}$

Positive and negative life experiences. Whereas the items (or composites) of primary interest in this study pertained to perspectives used to consider positive and negative events, as well as self-rated happiness, a set of four additional items (anticipating a feature of our next two studies) asked participants to describe both a specific incident in the past that made them happy and a specific incident that made them unhappy. After identifying both a "happy" and "unhappy" event, respondents were then asked to indicate how often they found themselves thinking about each of these experiences today (using a 7-point scale anchored at $1=$ almost never and 7 = almost always, with a midpoint of $4=$ fairly often). The positive events included memorable postmilitary service trips, first romances, much-valued gifts from parents, and achievement of awards and recognitions. The negative events ranged from the relatively mundane (e.g., separation from a girlfriend, rebukes suffered during military service) to the deeply significant (e.g., parental death or divorce, the death of a friend in military service).

\section{Results}

\section{Happiness-Enhancing and Happiness-Diminishing Endowment}

We first considered items and composites that asked participants to assess the extent to which past positive events-and/or thoughts about such events - constitute a continuing source of present happiness through the process of endowment (PE), and the extent to which past negative events - and/or thoughts about such eventsdiminish happiness through the process of endowment (NE). The mean level of endorsement of each item and the relevant composites by very happy, moderately happy, and unhappy respondents, as well as the relevant correlations between these means and the participants' self-reported happiness, are presented in Table 1.

As predicted, the correlation between the composite rating on the PE subscale and self-rated happiness on the 4-item SHS was positive in direction and highly significant, $(r=.31, p=.002)$. Inspection of the means in Table 1 suggests relatively high levels of endorsement (means above the midpoint on the relevant 7-point scales) by all three SHS groups, with the self-rated very happy group consistently endorsing PE items more than the unhappy group and with the mean for the moderately happy group falling somewhat closer to the mean for the unhappy group than that for the very happy group.

Consistent with much previous evidence regarding a positive bias in reports of happiness and life satisfaction (Bradburn, 1969; Campbell, Converse, \& Rodgers, 1976; Diener \& Diener, 1996;

\footnotetext{
${ }^{4}$ Respondents labeled as "unhappy" were those whose SHS scores were less than 4.50, and respondents labeled as "happy" were those whose SHS scores were higher than 5.75. The "moderately happy" group thus consisted of respondents whose scores on the 4-item composite fell between those "cut-off points."

${ }^{5}$ Participants in all three studies also completed the Life Orientation Test (a measure of dispositional optimism; Scheier \& Carver, 1985) and the SWLS. We describe these measures, and discuss correlations involving them, only in our report of Study 3, where the availability of a larger sample size, and our ability to use the original rather than translated versions of the scale, make our analyses more suitable.
} 
Table 2

Positive Contrast (PC) and Negative Contrast (NC) Items, Mean Endorsement Levels by Subjective Happiness Scale (SHS) Groups, and Correlations Between SHS and Level of Endorsement (Study 1)

\begin{tabular}{|c|c|c|c|c|}
\hline Items & Very happy & Moderately happy & Unhappy & $r$ \\
\hline $\begin{array}{l}\text { The comparison of the present with unhappy past events makes me feel } \\
\text { content and grateful. (PC) }\end{array}$ & 3.93 & 3.90 & 3.74 & .06 \\
\hline $\begin{array}{l}\text { Thinking about difficult times in the past helps me to feel good about } \\
\text { the present. (PC) }\end{array}$ & 3.43 & 3.80 & 3.41 & .05 \\
\hline $\begin{array}{l}\text { When I recall unhappy events in the past, I realize that my life today is } \\
\text { not as bad as it could have been. (PC) }\end{array}$ & 3.67 & 4.10 & 3.74 & -.03 \\
\hline $\begin{array}{l}\text { Sometimes, when things are not going well, it helps me to think of ways } \\
\text { in which things used to be even worse. (PC) }\end{array}$ & 3.60 & 3.58 & 3.33 & .02 \\
\hline PC composite & 3.66 & 3.84 & 3.56 & .04 \\
\hline $\begin{array}{l}\text { When I recall particular happy events in the past, the contrast with the } \\
\text { present makes me a little bit sad and depressed. (NC) }\end{array}$ & 1.90 & 2.55 & 3.17 & $-.40^{* * * *}$ \\
\hline $\begin{array}{l}\text { I often think about ways in which things have gotten worse for me than } \\
\text { they used to be. (NC) }\end{array}$ & 1.60 & 2.08 & 2.81 & $-.37^{* * * *}$ \\
\hline $\begin{array}{l}\text { When I think of happy events in the past, I realize that my life today is } \\
\text { not as good as it should have been. (NC) }\end{array}$ & 1.93 & 2.38 & 2.93 & $-.31^{* *}$ \\
\hline NC composite & 1.81 & 2.33 & 2.95 & $-.44^{* * * *}$ \\
\hline
\end{tabular}

${ }^{* *} p<.01 .{ }^{* * *} p<.001$.

Watson, Clark, \& Tellegen, 1988), respondents generally endorsed the five NE items much less than they endorsed the PE items, $t(96)=16.81, p<.001$. However, as predicted, the tendency to endorse these items was negatively correlated with participants' SHS scores $(r=-.42, p<.001)$, with the self-rated moderately happy group falling roughly midway between the unhappy and very happy groups on most items. Not surprisingly, the correlation between SHS and the difference between the two composite ratings (i.e., PE minus NE) was also highly significant ( $r=.53, p<$ .001 ), suggesting that the tendency to focus on, and be affected by, positive memories more than negative ones was indeed associated with self-reported happiness.

\section{Happiness-Diminishing and Happiness-Enhancing Contrast}

Having confirmed our straightforward predictions about the association between self-reported happiness and the magnitude of endowment effects regarding positive and negative past events, we now turn our attention to the less straightforward question of contrast effects (see Table 2). Again, our working hypotheses, following the analysis offered by Tversky and Griffin (1991), were (1) that the tendency to diminish happiness by contrasting present circumstances and feelings with more positive circumstances and feelings in the past (NC) would be associated with lower SHS scores, and (2) that the tendency to enhance happiness by contrasting present circumstances and feelings with more negative circumstances and feelings in the past (PC) would be associated with higher SHS scores.

The first of these hypotheses was clearly confirmed. The correlation between SHS scores and the NC composite proved to be highly significant $(r=-.44, p<.001)$, with happy participants endorsing the relevant items least, unhappy participants endorsing them most, and moderately happy participants endorsing them to a moderate degree. The second hypothesis, however, was not confirmed. Indeed, although participants overall endorsed the PC items more than the NC items, $t(96)=9.68, p<.001$, the correlation between SHS scores and the PC composite was close to zero $(r=.04)$, with the three SHS groups showing very similar levels of endorsement. In other words, while self-reported unhappiness was associated with happiness-diminishing contrasts between the present and a happier past, there was no tendency for happiness to be associated with contrasts involving a gloomier past.

\section{Additional Reflections About the Past}

Three individual items from the initial battery that involved neither endowment nor contrast nevertheless offer evidence that self-reported unhappiness is associated with endorsement of negative sentiments about previous unhappy life experiences, although of course some caution is appropriate in considering correlations involving single items. Self-reported happiness on the SHS scale was negatively correlated with endorsement of the statement, "There are some events in my childhood that I wish I could forget" $(r=-.35, p=.001)$, and positively correlated with the statement, "When I think of past events, I never feel regret" $(r=.29, p=$ .005). The single battery item that most distinguished happy participants from unhappy ones however, was a statement about the present that is essentially just an expression of current happiness (i.e., "I think my life is absolutely wonderful," $r=.59, p<.001$ ).

Furthermore, while happiness was not correlated with the drawing of solace from contrasts between the present and more difficult times in the past, the results for three other items that cited positive consequences of negative past events are worth noting. SHS scores proved to be positively correlated with endorsement of the statements: "I believe that positive thinking is a good way to deal with difficulties" $(r=.36, p<.001)$, "In dealing with disappointment and adversity, I am able to keep a sense of humor" $(r=.37, p<$ $.001)$, and "Failures in the past have taught me even more important lessons than have successes" $(r=.22, p=.03)$. 
Responses to two other individual items in Study 1 reveal a difference in the types of memories that happy versus unhappy participants regard as most vivid and presumably most memorable (although the wording of those items made no explicit mention of the effects of such past events on the participants' present feelings). Level of endorsement of the statement, "My most vivid memories about the past are about happy events," showed a highly significant positive correlation with SHS scores $(r=.39, p<$ .001 ), while level of endorsement of the statement, "My most vivid memories about the past are about unhappy events," showed a highly significant negative correlation with happiness $(r=-.32$, $p=.001$ ). Interesting to note, however (and in contrast to the case for vividness of memories described above), when we examined responses to items asking participants how often they found themselves currently thinking about the positive event and the negative event they had stipulated, the association between SHS and the relevant difference score, although positive, did not reach conventional levels of statistical significance $(r=.13, p>.10)$.

\section{Discussion}

Respondents, even those with SHS scores suggesting relative unhappiness, generally endorsed items citing ways of thinking about past events that made them happy more than items citing ways of thinking that made them unhappy. In the case of items involving endowment of positive and negative past events, and in the case of items involving a contrast between the present and a happier past, our data revealed the predicted association between the relevant tendencies and participants' self-reported happiness. That is, relatively happier participants tended to endow past positive events more, to endow past negative events less, and to contrast the present with a more positive past less, than did relatively unhappy participants.

Contrary to our working hypothesis, however, we found no association between SHS scores and endorsement of items involving happiness-enhancing contrasts between the present and negative events or bad times in the past. It is possible that happy respondents failed to endorse such $\mathrm{PC}$ items more than their peers because they were disinclined to see much of their past as unhappy (or, alternatively, perhaps to perceive benefits arising from such experiences that rendered them less unhappy in retrospect). However, the fact that very happy, moderately happy, and unhappy respondents all endorsed the sentiments in these items to at least a moderate degree suggests that all three groups do engage in such happiness-enhancing, or unhappiness diminishing contrast, and that they do so with equal frequency and effectiveness.

\section{Study 2}

\section{Method}

\section{Participants}

In this study, participants were 53 students (43 men, 10 women, all Jewish, and all enrolled in a computer science class) from the Interdisciplinary Center in Herzliya. The respondents, whose ages ranged from 21 to 30 years $(M=24)$, received course credit but no monetary compensation.

\section{Procedure}

As in Study 1, the questionnaire was sent to participants as an e-mail attachment, and they were invited to complete it and return it via e-mail attachment within a week if they wished to receive course credit. Participants were informed that the questionnaire dealt specifically with thoughts and memories regarding their military service, and virtually all of the items dealt with that experience. They were instructed to try to be "as honest and accurate as possible about their sentiments," and it was emphasized that there were "no right or wrong answers."

The initial set of items sought standard demographic information. These items were followed by some specific questions about the nature of the respondents' military service, and an item that required them (in a counterbalanced order) to stipulate and briefly describe both the "most positive event or aspect of their service" and "the most negative event or aspect of their service." (No effects involving this "order" variable were found.) In each case, after participants had indicated and described the relevant event, they were asked to answer an open-ended question regarding the event and its significance for their thoughts and feelings today.

In the case of the positive event, the open-ended question asked them specifically about the positive impact of the event, and then invited them to also indicate negative effects, if any. Conversely, in the case of the negative event, they were asked specifically about the negative impact of the event, but also invited to indicate positive effects. After answering the relevant open-ended question, participants were then presented with nine items in the form of statements about the aftermath of their military experience, some pertaining to endowment effects and some pertaining to contrast effects. The wording of these items closely paralleled the wording of items pertaining to more general life experiences that was used in Study 1. These items were accompanied by three other items that concerned the extent to which participants discussed those experiences with military comrades, friends, and family members, and to what extent they enjoyed such discussions.

\section{Measures}

Positive and negative life experiences. As noted above, participants answered questions about their endowment and contrast tendencies with respect specifically to their "most positive experience or aspect of their military service," as well as to their "most negative experience or aspect of their military service." Most positive experiences of service typically included important friendships made, accomplishment of dangerous and/or important missions, and recognitions received. Most negative experiences typically included loss of friends and people under their command, difficult dealings with Palestinian civilians, and frustrations with the military bureaucracy. Participants also indicated how often they thought about the relevant experience using a 7-point scale $(1=$ almost never, 4 = fairly often, and $7=$ almost always $)$.

Endowment and contrast. The questionnaire administered to participants in this study included happiness-enhancing and happiness-diminishing endowment and contrast statements similar to those employed in Study 1. However, in this study, the items were adapted to focus on participants' specific military experiences (see Tables 3 and 4 for a list of all individual items). Agreement with each item was indicated on a 7-point scale $(1=$ 
Table 3

Positive Endowment (PE) and Negative Endowment (NE) Items, Mean Endorsement Levels by Subjective Happiness Scale (SHS) Groups, and Correlations Between SHS and Level of Endorsement (Study 2)

\begin{tabular}{|c|c|c|c|c|}
\hline Items & Very happy & Moderately happy & Unhappy & $r$ \\
\hline $\begin{array}{l}\text { The memory of this positive event is a continuing source of my } \\
\text { happiness and well-being even today. (PE) }\end{array}$ & 4.88 & 4.22 & 3.67 & $.36^{* *}$ \\
\hline $\begin{array}{l}\text { When I think about this positive event, I realize how this event has } \\
\text { enriched my life. (PE) }\end{array}$ & 5.82 & 5.11 & 4.61 & $.36^{* *}$ \\
\hline $\begin{array}{l}\text { When I think about this positive event, I realize how fortunate I have } \\
\text { been in my life. (PE) }\end{array}$ & 4.71 & 4.33 & 3.83 & .26 \\
\hline PE composite & 5.14 & 4.56 & 4.04 & $.36^{* *}$ \\
\hline $\begin{array}{l}\text { The memory of this negative event is a continuing source of my } \\
\text { unhappiness and dissatisfaction even today. (NE) }\end{array}$ & 1.94 & 2.67 & 3.06 & $-.37^{* *}$ \\
\hline $\begin{array}{l}\text { When I think about this negative event, sometimes it makes me feel } \\
\text { sad or depressed. (NE) }\end{array}$ & $\begin{array}{r}1.82 \\
1.53\end{array}$ & 2.56 & 2.94 & $-.37^{* *}$ \\
\hline When I think about this negative event, I feel sorry for myself. (NE) & 1.53 & 1.44 & 2.39 & $-.41^{* *}$ \\
\hline NE composite & 1.76 & 2.22 & 2.80 & $-.44^{* * * *}$ \\
\hline
\end{tabular}

${ }^{* * *} p<.01 .{ }^{* * * *} p<.001$.

strongly disagree, 7 = strongly agree). The internal consistency was .88 and .84 , respectively, for the three-item PE and NE composites, and .74 and .54 , respectively, for the three-item PC and NC composites. In addition to statements about the endowment and contrast perspectives used to consider participants' most positive and negative military experiences, three other statements mentioned talking about the positive or negative experiences with friends, family members, and former military comrades.

Happiness. Respondents rated their level of happiness using the same (translated) SHS instrument as in Study 1. Once again, although our statistical analyses consisted largely of correlations between respondents' endorsement of happiness-enhancing and happiness-diminishing endowment and contrast items and selfratings of happiness, we also report mean responses on the PE, NE, $\mathrm{PC}$, and NC subscales, and on the individual items comprising these subscales. The means are shown for three groups of respondents classified (on the basis of similar but not identical cut-off points to those employed in Study 1$)$ as very happy $(n=17)$, moderately happy $(n=18)$ and unhappy $(n=18) .{ }^{6}$ Again, as in Study 1, we report these means not to suggest categorical distinctions but to convey absolute levels of endorsement and clarify the nature of the relevant response distributions.

\section{Results}

\section{Positive and Negative Life Experiences}

Before considering levels of endorsement for statements about endowment and contrast, we first had a pair of raters (blind to the respondents' SHS scores) read the descriptions of the positive and negative events stipulated by each participant, and assess the degree (i.e., intensity) of their relative positivity or negativity. These ratings revealed a high degree of interrater agreement regarding both the positive (intraclass correlation coefficient [ICC] $=.80$ ) and the negative ( $\mathrm{ICC}=.90$ ) events.

More important, our raters' assessments suggested no systematic relationship between participants' self-rated happiness and the intensity of the events they stipulated and later reflected upon with respect to endowment and contrast. In the case of the positive events, the correlation between SHS scores and the mean of the two raters' assessments was $r=-.03, p=.85$. In the case of the negative events stipulated, the correlation in question was $r=-.18, p=.21$.

Examination of group means revealed that very happy participants reported thinking about their positive experiences more often than their negative ones $(M \mathrm{~s}=4.41$ vs. 3.18), $t(16)=3.98, p=.001$, whereas unhappy participants reported thinking about their negative experiences as often as their positive ones $(M \mathrm{~s}=3.44$ vs. 3.50$)$, $t(17)<1$. In the case of the moderately happy participants, not surprisingly, the difference between these means ( $M=3.56$ vs. 3.06) was of intermediate magnitude, but again not statistically significant $t(17)<1$. What is more interesting, perhaps, is the fact that this moderately happy group most resembled the unhappy group in how often they think about positive events and most resembled the happy group in how often they think about negative events.

An additional set of items addressing the impact of past events on memory and happiness asked participants to what extent they talked to others about their military experiences with previous military comrades and with family members. For neither measure, however, were responses significantly correlated with the participants' SHS scores $(r=.09$ and $r=-.11$, respectively, both $p$ values $>.10)$.

\section{Happiness-Enhancing and Happiness-Diminishing Endowment}

As in Study 1, responses to individual questionnaire items pertaining to the endowment effects of past events were averaged to provide $\mathrm{PE}$ and $\mathrm{NE}$ composites, as well as the difference

\footnotetext{
${ }^{6}$ To achieve a rough trichotomy for the purpose of presenting means for the three subgroups, it was necessary to use slightly different "cutting points" in Study 2 than in Study 1. Thus, the "unhappy" group included respondents with means on the SHS of 4.50 or less, the "moderately happy" group included those with means between 4.75 and 5.50, and the "happy" group included those with means on the scale of 5.75 or more. As in Study 1, of course, the correlations between SHS and responses to the various endowment and contrast scales are in no way affected by these choices of cutting points.
} 
Table 4

Positive Contrast (PC) and Negative Contrast (NC) Items, Mean Endorsement Levels by Subjective Happiness Scale (SHS) Groups, and Correlations Between SHS and Level of Endorsement (Study 2)

\begin{tabular}{|c|c|c|c|c|}
\hline Items & Very happy & Moderately happy & Unhappy & $r$ \\
\hline $\begin{array}{l}\text { When I think about this event, I realize it gave me a better sense of } \\
\text { proportion. (PC) }\end{array}$ & 4.06 & 4.72 & 4.94 & -.15 \\
\hline $\begin{array}{l}\text { When I think about this event, I realize that it provided valuable lessons } \\
\text { that help me today. (PC) }\end{array}$ & 4.47 & 4.89 & 4.61 & -.01 \\
\hline $\begin{array}{l}\text { When I recall this event, I feel I have no reason to complain about } \\
\text { anything in the present. (PC) }\end{array}$ & 2.18 & 3.11 & 2.39 & .04 \\
\hline PC composite & 3.57 & 4.24 & 3.98 & -.05 \\
\hline $\begin{array}{l}\text { Thinking about this event and contrasting it with my life today sometimes } \\
\text { makes me feel sad or depressed. (NC) }\end{array}$ & 1.53 & 1.61 & 1.89 & $-.30^{*}$ \\
\hline $\begin{array}{l}\text { When I think about this event, I realize that my life now is not as good } \\
\text { as it should have been. (NC) }\end{array}$ & 1.24 & 1.28 & 2.44 & $-.54^{* * * *}$ \\
\hline $\begin{array}{l}\text { I notice that when I think about this event, I experience less joy from } \\
\text { other positive events. (NC) }\end{array}$ & 1.41 & 1.61 & 1.78 & -.14 \\
\hline $\mathrm{NC}$ composite & 1.39 & 1.50 & 2.04 & $-.46^{* * * *}$ \\
\hline
\end{tabular}

${ }^{*} p<.05{ }^{* * * *} p<.001$.

between these two composites. In this case, however, the events that participants reflected upon were particular experiences that took place during their military service. Correlations between participants' self-reported happiness and responses for the relevant items and composites are presented in Table 3, as are means for our three SHS groups. Once again, our straightforward hypotheses regarding happiness-enhancing endowment of positive past events and happiness-diminishing endowment of negative past events are clearly confirmed for the two composite measures $(r=.36, p=$ .008 , and $r=-.44, p=.001$, respectively) and for the difference between these two composites as well $(r=.53, p<.001)$.

Examination of the means in Table 3 reveals that participants, overall, endorsed items pertaining to the positive endowment effect of specific past positive events much more than they endorsed items pertaining to the negative endowment effects of specific past negative events, $t(52)=6.86, p<.001$. That examination also reveals a pattern of responses for the three separate SHS groups that is fully consistent with the relevant correlations. That is, very happy respondents endorsed the PE items much more than did unhappy respondents, whereas the reverse was true for NE items, with the moderately happy respondents showing levels of endorsement between these two groups on both the PE and the NE items. In sum, positive past events and experiences appear to be a greater source of continuing happiness for participants who characterize their current level of happiness as relatively high, whereas unhappy past events and experiences appear to be a greater source of diminished happiness and/or continuing unhappiness for participants who characterize their current level of happiness as relatively low.

\section{Happiness-Diminishing and Happiness-Enhancing Contrast}

In the case of contrast items, our primary analyses once again involve correlations between participants' SHS scores and their responses both on individual $\mathrm{PC}$ and $\mathrm{NC}$ items and on the relevant composites. However, group means for these items and composites for very happy, moderately happy, and unhappy respondents are also presented in Table 4. Our analyses replicated the pattern of contrast findings found in Study 1. That is, we found a highly significant negative correlation between respondents' SHS scores and their tendency to endorse items that mentioned the happiness-diminishing or unhappinessenhancing effects of contrasting the present with happier times-in this case, specific happy events and experiences during their periods of military service $(r=-.46, p<.001)$. Inspection of the group means in Table 4 shows relatively low overall levels of endorsement by respondents in general but considerably lower levels by very happy participants than unhappy ones, with moderately happy respondents offering levels of endorsement that were intermediate between the other two groups, although closer to those of the unhappy than the very happy group.

Again, however, our data provided little evidence to suggest a correlation between participants' SHS scores and their tendency to endorse items that tapped the happiness-enhancing (and/or unhappiness-diminishing) effects of contrasting the present with particularly difficult or painful military experiences. Indeed, the correlation in question was close to zero both for the composite measure $(r=-.05)$ and for each of the three items averaged to provide that composite (see Table 4). Inspection of the means for the three SHS groups confirms that levels of endorsement were relatively similar for the very happy and the unhappy group, and it also shows (as was the case in Study 1) that the moderately happy participants actually tended to endorse these items slightly (but not significantly) more than either of the other two SHS groups.

\section{Discussion}

In summary, in Study 2 we once again found that respondents endorsed items involving ways of thinking about past events-in this case, specific past events pertaining to the highs and lows of their military experience - that made them happy more than they endorsed items involving ways of thinking that made them unhappy. We also found the same pattern of correlations and differences in mean responses as a function of 
participants' self-characterization of their own happiness that had been apparent in Study 1. Relatively happy respondents again endorsed items citing positive endowment effects more, and items citing negative endowment effects less, than relatively unhappy respondents. Relatively unhappy respondents again endorsed items citing the negative effects of contrasting their present circumstances and experiences with the specific positive military experiences they had stipulated. But we again found no linear relationship between self-rated happiness and the tendency to boost present feelings of happiness (and/or diminish present feelings of unhappiness) by contrasting present circumstances with negative military experiences in the past.

The failure to find an association between self-rated happiness and the tendency to elevate happiness through contrast between their present circumstances and particularly difficult or painful past experiences is subject to varying interpretations, which we shall explore in more detail after considering the results of our third and final study. Regardless of its cause, however, this "failure" is informative insofar as it helps us to rebut any characterization of the results that we have reported thus far as an unsurprising tendency for more positive self-ratings of happiness to be associated with greater willingness to endorse statements that cite positive feelings and changes in feelings.

With the results of these two studies in mind, we now turn to our final study, which again examined the correlation between selfrated happiness and responses to questionnaire items involving endowment and contrast in reflecting on past positive and negative experiences. Study 3, however, examined the responses of a sample of American undergraduates who were somewhat younger than the Israeli participants in our two earlier studies, and unlikely to have had a single source of positive and negative experiences of the sort shared by all military veterans. Accordingly, participants in Study 3 were asked to reflect on an extremely positive and an extremely negative event of their own choosing from any domain of their past experience. This allowed us to examine differences in the type and intensity of events stipulated by relatively happy versus relatively unhappy respondents. Finally, in Study 3 we employed a larger sample of respondents than in our earlier studies, made use of a factor analysis in constructing our endowment and contrast scales, and considered correlations involving not only the SHS used in Studies 1 and 2, but also measures of optimism and life satisfaction.

\section{Study 3}

\section{Method}

\section{Participants}

A total of 231 college students ( 157 women and 74 men) at the University of California, Riverside, provided data for this study. Participants were recruited from introductory psychology classes and received class credit in exchange for their participation. Their mean age was 19.2 years, with a range from 18 to 45 . The ethnicity of the sample (in contrast to that of the relatively homogeneous Jewish Israeli population in our first two studies) reflected the diverse, although heavily Asian and Asian American, population at the Southern California university from which the sample was drawn. These ethnic percentages were Asian (43.7\%), White (13.9\%), Hispanic (12.6\%), African American (8.7\%), Hawaiian or Pacific Islander (7.4\%), American Indian (0.4\%), and "other" or "more than one" (13\%).

\section{Procedure}

To participate in this study, students accessed the Department of Psychology's subject pool database from which they could select among numerous research studies offering class credit. In contrast to the case in Studies 1 and 2, in which students responded to an e-mail attachment, participants in Study 3 were provided with the relevant web address and completed the study online from any venue (e.g., dorm room, campus computer lab, etc.) where they had Web access. Participants first answered a series of demographic questions. They then were asked to indicate (in an openended format) both a positive and a negative life experience, and, having done so, to respond to questionnaire items that dealt with their tendency to endow those past experiences and/or to contrast them with their present circumstances.

\section{Measures}

Positive and negative life experiences. As in Study 2, participants first identified and briefly wrote about one highly positive and one highly negative event in their lives (with order counterbalanced). But in this study, they were free to choose an event from any aspect of their lives. The specific instruction was to "identify one of the happiest [unhappiest] events you have experienced in your life and briefly describe this experience below." As in our two earlier studies, we asked participants to assess the extent to which these events continued to enhance or detract from their current state of happiness and well-being, but in this final study, we employed a formal factor analysis to create the relevant composite PE, NE, PC, and NC scales. We thus began with 44 items -11 written to potentially measure PE, 10 to measure NE, 12 to measure $\mathrm{PC}$, and 11 to measure $\mathrm{NC}$ - to which participants responded on 7-point scales $(1=$ not true of me, $7=$ completely true of me).

When participants were asked to assess the impact of the positive event they had described, we sought evidence of endowment and contrast by having them respond to a series of statements that began: "When I think about this positive (negative) event, I . . ." A factor analysis of 44 potential endowment and contrast items allowed us to "weed-out" 10 statements that did not load well with respect to the relevant constructs. That is, items that loaded on multiple factors or loaded weakly on a single factor were excluded. This process resulted in a final PE scale with nine items $(\alpha=.91)$, an NE scale with seven items $(\alpha=.93)$, a PC scale with seven items $(\alpha=.68)$, and an NC scale with nine items $(\alpha=.87)$. The content of these PE and NE items is presented in Table 5, and the content of the PC and NC items is presented in Table 6 .

Happiness assessment. As in Studies 1 and 2, participants' self-rated happiness was assessed by the four-item SHS, which they completed after responding to the relevant endowment and contrast items. The internal reliability of the SHS in this study was .88. As in our previous two studies, we tested the association between responses to the endowment and contrast scales of interest by examining the correlation between participants' SHS scores and 
Table 5

Positive Endowment (PE) and Negative Endowment (NE) Items, Mean Endorsement Levels by Subjective Happiness Scale (SHS) Groups, and Correlations Between SHS and Level of Endorsement (Study 3)

\begin{tabular}{|c|c|c|c|c|}
\hline Items & Very happy & Moderately happy & Unhappy & $r$ \\
\hline \multicolumn{5}{|l|}{ When I think about this positive event ... } \\
\hline I think about how happy it still makes me feel. (PE) & 6.55 & 6.11 & 5.72 & $.33^{* * * *}$ \\
\hline I feel like this event continues to lift my mood. (PE) & 6.03 & 5.49 & 5.03 & $.32^{* * * * *}$ \\
\hline I recognize the many ways in which it has enriched my life. (PE) & 6.13 & 6.03 & 5.03 & $.35^{* * * * *}$ \\
\hline I think about the positive effects that it has had on me. (PE) & 6.08 & 5.78 & 4.85 & $.34^{* * * *}$ \\
\hline It makes me happy. (PE) & 6.53 & 6.22 & 5.41 & $.39^{* * * * *}$ \\
\hline I think about how it has had a very positive impact on my life. (PE) & 6.06 & 5.88 & 5.05 & $.29^{* * * *}$ \\
\hline I feel happy all over again. (PE) & 6.09 & 5.80 & 4.96 & $.36^{* * * * *}$ \\
\hline I often smile or laugh. (PE) & 6.12 & 5.77 & 5.05 & $.35^{* * * *}$ \\
\hline I realize how fortunate I have been in my life. $(\mathrm{PE})$ & 6.31 & 6.14 & 5.32 & $.32^{* * *}$ \\
\hline PE composite & 6.21 & 5.91 & 5.16 & $.44^{* * * *}$ \\
\hline \multicolumn{5}{|l|}{ When I think about this negative event... } \\
\hline I think about the negative effects that it has had on me. (NE) & 3.86 & 4.28 & 4.51 & $-.20^{* * *}$ \\
\hline This event continues to make me feel depressed or sad. (NE) & 3.99 & 4.33 & 4.92 & $-.23^{* * * *}$ \\
\hline I think about how it has had a very negative impact on my life. (NE) & 3.06 & 3.82 & 4.23 & $-.27^{* * * *}$ \\
\hline I think about how unhappy this event still makes me feel. (NE) & 3.97 & 4.55 & 4.76 & $-.19^{* *}$ \\
\hline This event still hurts today. (NE) & 4.47 & 4.54 & 5.12 & $-.16^{*}$ \\
\hline I think about how this event continues to make me feel bad. (NE) & 3.69 & 3.97 & 4.46 & $-.20^{* * *}$ \\
\hline I feel unhappy all over again. (NE) & 3.46 & 3.94 & 4.31 & $-.18^{* *}$ \\
\hline NE composite & 3.79 & 4.21 & 4.62 & $-.24^{* * *}$ \\
\hline
\end{tabular}

${ }^{*} p<.05 . \quad{ }^{* *} p<.01 . \quad{ }^{* * *} p<.001$.

their responses to these scales. But to facilitate interpretation of those correlations (and give some sense of the absolute levels of endorsement of the relevant items), we again present means for very happy $(n=78)$, moderately happy $(n=79)$, and unhappy $(n=74)$ respondents. ${ }^{7}$

Life satisfaction. Before completing the SHS, participants also completed the five-item Satisfaction With Life Scale (SWLS; Diener, Emmons, Larsen, \& Griffin, 1985). Items on this scale consist of statements (e.g., "In most ways my life is close to my ideal" and "I am satisfied with my life") for which respondents indicated their level of agreement on 7-point Likert-type scales $(1=$ strongly disagree, $7=$ strongly agree $)$. The internal consistency of this self-report measure proved to be quite high $(\alpha=.88)$.

Optimism. The final instrument participants completed was the Life Orientation Test (LOT; Scheier \& Carver, 1985), which is a scale designed to measure dispositional optimism. Excluding four filler items, the LOT consists of eight statements (e.g., "In uncertain times, I usually expect the best" and "I always look on the bright side of things") to which participants responded using 5-point Likert-type scales $(0=$ strongly disagree, $4=$ strongly agree). The internal consistency of this measure was .80 .

\section{Results}

\section{Positive and Negative Life Experiences}

Two raters assessed the intensity or potential emotional impact of the positive and negative events described by our participants. Examination of these ratings revealed very high interrater agreement for the negative events (ICC $=.91$ ) and satisfactory, albeit somewhat lower, agreement for the positive events (ICC $=.68$ ). However, as in Study 2, no relationship emerged between the apparent intensity of the positive or negative events cited by respondents and the respondents' SHS scores $(r=.10$ and .06 , respectively). Indeed, on 7-point scales (anchored at $1=$ devoid of emotional significance and $7=$ extremely positive/negative), the mean ratings for the positive events described by very happy, moderately happy, and unhappy respondents were almost identical (4.17, 4.18, and 4.11, respectively, in the case of positive events, and $4.03,3.87$, and 3.87 , respectively, in the case of negative events). Thus, any association found between responses to the endowment and contrast items that pertained to the events stipulated by participants and those participants' SHS scores could not be an artifact of, or mediated by, differences in the objective positivity or negativity of the events specified by relatively happy versus relatively unhappy respondents.

\section{Happiness-Enhancing and Happiness-Diminishing Endowment}

Examination of the nine positive endowment items and the seven negative endowment items developed through factor analysis (see Table 5) replicated the results obtained for the less formally developed scales used in Studies 1 and 2. That is, respondents once again generally endorsed PE items $(M=5.77)$ more than NE items $(M=4.20), t(230)=12.42, p<.001$. Furthermore, there was a significant positive correlation between respondents' SHS scores and their endorsement of the PE items $(r=.44, p<$ .001 , for the relevant composite) and a negative correlation between SHS scores and endorsement of the NE items $(r=-.24$,

\footnotetext{
${ }^{7}$ Participants with SHS scores of 4.25 and below were classified as unhappy; those with SHS scores between 4.50 and 5.25 were classified as moderately happy; and those with SHS scores of 5.50 and greater were classified as very happy.
} 
Table 6

Positive Contrast (PC) and Negative Contrast (NC) Items, Mean Endorsement Levels by Subjective Happiness Scale (SHS) Groups, and Correlations Between SHS and Level of Endorsement (Study 3)

\begin{tabular}{|c|c|c|c|c|}
\hline Items & Very happy & Moderately happy & Unhappy & $r$ \\
\hline \multicolumn{5}{|l|}{ When I think about this negative event ... } \\
\hline I realize how much better things are now. (PC) & 4.49 & 4.47 & 3.77 & .12 \\
\hline I feel like it has made other negative experiences more bearable. (PC) & 4.58 & 4.67 & 4.32 & .07 \\
\hline The contrast with the present makes me feel grateful and pleased. (PC) & 4.88 & 4.85 & 4.00 & $.26^{* * * *}$ \\
\hline I realize that my current situation isn't as bad as it could be. (PC) & 5.74 & 5.23 & 4.49 & $.36^{* * * * *}$ \\
\hline I compare this event with other negative experiences I have had. (PC) & 3.45 & 4.05 & 3.51 & -.03 \\
\hline feel like other negative experiences aren't quite as bad. (PC) & 4.62 & 4.23 & 4.19 & .12 \\
\hline I see how much worse things used to be. (PC) & 3.40 & 3.92 & 3.31 & .06 \\
\hline PC composite & 4.45 & 4.49 & 3.94 & $.22^{* * *}$ \\
\hline \multicolumn{5}{|l|}{ When I think about this positive event ... } \\
\hline I notice that I experience less joy from other positive events. (NC) & 2.72 & 3.09 & 3.04 & -.12 \\
\hline I notice that other positive experiences are now less thrilling. (NC) & 2.60 & 2.95 & 2.59 & .01 \\
\hline I realize how much worse things are now. (NC) & 1.74 & 2.41 & 2.45 & $-.25^{\text {**** }}$ \\
\hline The contrast with the present makes me a little sad or depressed. (NC) & 2.18 & 3.01 & 3.16 & $-.24^{* * * *}$ \\
\hline I feel like other positive experiences just don't quite measure up. (NC) & 2.78 & 3.18 & 2.97 & -.03 \\
\hline I see how much better things used to be. (NC) & 2.22 & 3.03 & 2.54 & -.10 \\
\hline I realize that my current situation isn't as happy as it could be. (NC) & 2.18 & 3.23 & 3.23 & $-.33^{* * * * *}$ \\
\hline $\begin{array}{l}\text { I feel like this event has made me enjoy other positive experiences less. } \\
\text { (NC) }\end{array}$ & 2.15 & 2.84 & 2.35 & -.11 \\
\hline $\begin{array}{l}\text { I think about the "good old days" when the event occurred and it makes me } \\
\text { sad. (NC) }\end{array}$ & 2.87 & 3.62 & 3.64 & $-.16^{*}$ \\
\hline NC composite & 2.39 & 3.04 & 2.89 & $-.21^{* *}$ \\
\hline
\end{tabular}

${ }^{*} p<.05 . \quad{ }^{* *} p<.01 .{ }^{* * *} p<.001$.

$p<.001)$. The correlation between respondents' happiness scores and the difference in levels of endorsement for the two types of endowment items is also noteworthy $(r=.45, p<.001)$. Inspection of mean levels of endorsement of the relevant endowment items by the three SHS groups, as shown in Table 5, further shows that the very happy respondents endorsed PE items more than did unhappy ones, whereas unhappy respondents endorsed NE items more than did very happy ones, with moderately happy respondents offering intermediate levels of endorsement for the items on both endowment scales.

\section{Happiness-Enhancing and Happiness-Diminishing Contrast}

The seven items dealing with the contrast between negative past experiences and the more positive present (i.e., PC) and the nine items dealing with the contrast between positive past experiences and the less positive and exciting present (i.e., NC) are presented in Table 6. Once again, participants in general were much more inclined to endorse items that involved happiness-enhancing rather than happiness diminishing contrast $(M \mathrm{~s}=4.44 \mathrm{vs}$. 2.77 , for the $\mathrm{PC}$ and NC composites), $t(230)=15.98, p<.001$.

When we examine the association between SHS and endorsement of the two types of items, we find some departures from the findings of our first two studies. While we once again see a negative correlation between participants' SHS scores and their tendency to endorse the $\mathrm{NC}$ items, the correlation in question, although statistically significant, proved to be somewhat smaller in magnitude $(r=-.21, p<.01)$, and less consistent across items, than had been the case in our two earlier studies. Indeed, an inspection of mean responses for the three SHS groups reveals that while unhappy participants generally endorsed the NC items more strongly than happy participants, in this study it was the moderately happy participants who tended to endorse these items most strongly of all.

When we turn our attention to the contrast items that measure the tendency to enhance happiness or diminish unhappiness by contrasting present circumstances with particularly difficult or unhappy experiences in the past, we find an even more notable departure from the results of our two Israeli studies. Recall that in those studies the correlation between responses to virtually all of these items and participants' SHS scores had been close to zero. In Study 3, although the relationship between participants' SHS scores and their endorsement of several of the individual PC items again was close to zero, the relevant correlation for the PC composite was significant $(r=.22, p<.01)$. As apparent in the top portion of Table 6 , the items that contributed most heavily to the observed correlation were "The contrast with the present makes me feel grateful and pleased" $(r=.26)$ and "I realize that my current situation isn't as bad as it could be" $(r=.36)$. In short, our American participants clearly responded somewhat differently to the relevant "contrast" items - a finding we deal with further in our discussion.

\section{Relationships Between Endowment and Contrast Subscales}

We postponed consideration of correlations between the relevant endowment and contrast subscales until Study 3 largely because it utilized a greater number of research participants and more items in each composite. The relevant analyses (see Table 7) revealed moderate positive correlations between $\mathrm{PE}$ and $\mathrm{PC}$ and 
Table 7

Correlations Among Endowment and Contrast Perspectives and Additional Outcomes

\begin{tabular}{|c|c|c|c|c|c|c|c|}
\hline Items & $\mathrm{PE}$ & $\mathrm{NE}$ & $\mathrm{PC}$ & $\mathrm{NC}$ & SHS & SWLS & Life orientation test \\
\hline Positive endowment (PE) & - & -.003 & $.24^{* * * *}$ & $-.14^{*}$ & $.44^{* * * *}$ & $.42^{* * * *}$ & $.33^{* * * *}$ \\
\hline Negative endowment (NE) & & - & $-.14^{*}$ & $.26^{* * *}$ & $-.24^{* * * *}$ & $-.18^{* *}$ & $-.24^{* * * *}$ \\
\hline Positive contrast (PC) & & & - & .09 & $.22^{* * * *}$ & $.22^{* * * *}$ & $.18^{* *}$ \\
\hline Negative contrast (NC) & & & & - & $-.21^{* * * *}$ & $-.16^{*}$ & $-.23^{* * * *}$ \\
\hline Subjective Happiness Scale (SHS) & & & & & - & $.68^{* * * *}$ & $.64^{* * * * *}$ \\
\hline Satisfaction With Life Scale (SWLS) & & & & & & - & $.49^{* * * *}$ \\
\hline
\end{tabular}

${ }^{*} p<.05 . \quad{ }^{* *} p<.01 .{ }^{* * *} p<.001$.

between $\mathrm{NC}$ and NE; and weaker, but still statistically significant, negative correlations between PE and NC and between NE and PC. These four significant correlations are in accord with what one might expect given the relationship of each composite to the SHS measure, but not so high as to raise the issue of whether the relevant subscales are measuring independent constructs. The absence of a significant relationship between $\mathrm{PE}$ and $\mathrm{NE}$ and between PC and NC likely reflects the impact of an obvious methodological artifact. That is, any overall tendency to agree with statements involving endowment or to agree with those involving contrast would attenuate the respective expected negative relationships between positive and negative endowment and between positive and negative contrast. ${ }^{8}$

\section{Correlations Between Endowment and Contrast Perspectives and Additional Measures}

Study 3 allowed us to examine the association of happinessenhancing and happiness-diminishing perspectives on past events not only with the SHS measure reflecting self-reported dispositional happiness but also with general satisfaction with life and optimism. The correlations, reported in Table 7, make it clear that the relevant measures of personal well-being all show the same relationships with the PE, NE, PC, and NC composites as the SHS measure featured in our three studies. That is, Study 3 participants who show a greater tendency to savor or endow positive events and to contrast the present with negative past experiences in a way that enhances their present happiness not only score higher on the SHS, but also report greater satisfaction with their lives and display more optimism about the future. Conversely, participants who show a greater tendency to dwell on or endow negative events and contrast the present with positive past experiences in a way that could diminish their present happiness not only score lower on the SHS; they also report lower satisfaction with their lives and display less optimism about the future. This finding suggests that not just self-rated happiness, but a variety of well-being indicators and positive outlook are associated with positive endowment and contrast processes in considering memories of good and bad events.

\section{Discussion}

Once again, we found that regardless of how respondents rated their level of happiness on the SHS, they tended to endorse statements about the positive effects of past experiences on their present sense of well-being more than they endorsed statements about the negative effects of past experiences. We also found that among an ethnically diverse sample of U.S. college students, as had been the case in our two studies with a homogeneous sample of Israeli students, higher levels of self-reported happiness were associated with a greater tendency to savor or endow positive past events and to refrain from dwelling on or endowing negative past events-notwithstanding the fact that, as in Study 2, the "objective" positivity of the positive events and negativity of the negative events cited did not differ as a function of respondents' SHS ratings.

However, in the case of statements involving contrast between the past and the present, we found a somewhat different pattern of results for U.S. students than we had found for Israeli students. In particular, in Study 3, a somewhat weaker negative correlation emerged between self-reported happiness and the tendency to

\footnotetext{
${ }^{8}$ In light of the correlations found in Study 3, it is interesting to consider the results of parallel analyses in Study 1, in which the questionnaire items similarly dealt with memories of positive and negative events in general (as opposed to specific military events, as in Study 2). Despite the differences in specific item content, in four cases the relevant correlations proved to be rather similar in the two studies. That is, in Study 1, the correlation between PE and PC was again moderate and positive $(r=.28)$, the correlations between $\mathrm{PE}$ and $\mathrm{NC}$ was again slightly negative $(r=$ $-.08)$, the correlation between $\mathrm{PC}$ and $\mathrm{NC}$ was modestly positive $(r=$ .13), and the correlation between PE and NE was, again, close to zero $(r=.06)$. But in two cases, the correlations in question were quite different and merit some comment. First, whereas the correlation between NE and PC had been negative in direction, albeit moderate in magnitude, in the case of the U.S. sample in Study 3, it was moderately positive $(r=.23)$ in Study 1. The difference between these two correlations becomes less surprising when one recalls that the Israeli and American samples differed in terms of the relationship between PC and SHS. The U.S. sample, it will be recalled, showed a significant, albeit not large, correlation $(r=.22)$, whereas the Israeli sample showed virtually no relationship $(r=.04)$. The other difference in magnitude of correlations, that between NE and NC ( $r=.66$ in Study 1 compared with $r=.26$ in Study 3), is perhaps more problematic. Indeed, on the basis of the Israeli data alone, we might have concluded that the two scales were tapping the same sentiments (i.e., the sentiment that thinking about the past produces some unhappiness) and that such sentiments were endorsed more by unhappy respondents than happy ones. While speculation about the reasons for the difference in results between the two studies would take us well beyond any available data, we can take some comfort from the fact that the correlation between the two scales was notably lower in Study 3, while in both studies each of the subscales showed the predicted correlation with the SHS.
} 
contrast present circumstances with positive past experiences than in the two previous studies. Furthermore, and perhaps more notably, both on the relevant composite measure and on some specific items involving contrast between present circumstances and negative past experiences, we now, for the first time, found a positive correlation between endorsement of the relevant items and scores on the SHS.

Did the between-studies differences in responses to the relevant contrast measures reflect a difference in the ethnic makeup and life experiences of the groups sampled? Did it reflect a difference in the method of generating the items included in the relevant scales, a difference in the past events that participants were asked to contemplate (i.e., military experiences that were similar for the participants vs. nonmilitary experiences that differed for the participants)? Or was the difference in findings simply a matter of chance? We cannot answer this question with the data at hand, but the possibility of cultural differences in the ways people seek to maintain a sense of well-being, or perhaps even in the strategies they are forced to utilize in light of their particular histories, is obviously an interesting topic for future research.

Finally, Study 3 established that the correlations between selfreported happiness and the endowment and contrast measures in question were not products of the particular self-report measure that we employed. Indeed, the relevant correlations were of very similar magnitude when we substituted measures of life satisfaction or optimism for the SHS scale, even though the semantic content of these two measures did not specifically refer to happiness to the same degree as the SHS.

\section{General Discussion}

In three studies, two conducted in Israel with a homogenous sample of students and one in the United States with an ethnically diverse (and somewhat younger) sample, we demonstrated an association between the levels of present happiness and well-being that people report and the ways they report thinking about, and/or the significance they report attaching to, their past positive and negative experiences. In so doing, we believe we have added to existing literatures that either have dealt more with mood than with temperament and/or concerned themselves only with a subset of memorial tendencies or strategies.

There is, of course, always a concern when one relies so heavily on self-report measures. With respect to self-reports of temperament, there really is no other option. When we say someone is happy (or unhappy), we mean that the individual sees himself or herself as such and, clinical exceptions aside, we would be reluctant to challenge a self-report on the basis of less direct measures. With respect to self-reported memories and sentiments about those memories, the issue is less clear-cut. Such sentiments might be explored through experience sampling or diary methodologies although, again, it is unclear that summary statements about those sentiments should be given less weight than the results of other procedures. The real issue, perhaps, as we shall discuss in more detail below, is whether the way one holds the past is a reflection as much as a source of one's temperament.

Our findings with regard to endowment were consistent in all three studies, and were consistent regardless of whether the respondents' reflections about the past concerned happy and unhappy past events in general, specific positive and negative mili- tary service experiences, or emotionally significant events in domains of the respondents' own choosing. That is, dispositional happiness, as measured in all three studies by a simple four-item self report scale (the SHS) and, in the case of Study 3, measures of life satisfaction and optimism, were consistently associated with the tendency to endow or savor positive past events and not to endow or dwell on negative past events.

Our findings concerning the relationship between self-reported happiness and happiness-enhancing versus happiness-diminishing contrasts of the present with the past were less straightforward. In Studies 1 and 2, Israeli SHS scores for respondents asked to reflect on their positive and negative experiences in general (Study 1) and on specific positive and negative military experiences they chose to describe (Study 2) proved to be negatively correlated with the tendency to contrast present circumstances with more positive past experiences in a way that diminished their happiness. This correlation was also apparent, albeit weaker, in the responses of the American participants in Study 3; moreover, the correlation in question was slightly misleading insofar as moderately happy respondents appeared to endorse the relevant questionnaire items somewhat more consistently than unhappy respondents.

The relationship between happiness-enhancing contrasts of the present with prior difficult or unhappy times was even less consistent. Whereas no association between these variables had been apparent in Studies 1 and 2, a positive correlation between this tendency and the SHS was found in Study 3 both for the relevant composite scale and for several specific items.

\section{Self-Report Correlations and the Issue of Causal Direction}

To what extent are the different ways of reflecting on positive and negative past experiences investigated in this article a source, and to what extent are they a reflection, of individuals' current state of happiness and well-being? We cannot answer this question on the basis of the current correlational data. We suspect that happiness of the sort with which we have been concerned in this research is in part (and/or for some individuals) a source that inspires, or makes natural, the relevant use of endowment and contrast. We suspect that it is also in part (or for some) a consequence of that use. Most of all, we suspect that the processes we have documented help happy people to sustain their happiness in the face of bad times or memories of such times, and to enhance their happiness in good times and in good memories. For less happy people, we see a more complex and dynamic process whereby endowment and contrast effects of both the happinessenhancing sort and the happiness-attenuating sort make their influence felt. In a sense, less happy people (as opposed to depressed individuals) do make an effort to enhance their sense of well-being with regard to memories. Moreover, as the mean happiness ratings in our study attest, although they sometimes fail, they generally succeed.

One unanticipated finding suggests an interesting cultural difference between Israelis and Americans, although additional evidence is obviously required before we can offer any firm conclusions. Only in our American sample (and only on certain questionnaire items) did we find more evidence of the use of positive contrast in the case of very happy individuals than that of unhappy individuals. The Israelis showed no such correlation 
between temperament and happiness-enhancing contrast between bad times in the past and present better times. In general, however, it appears that happy people do not work harder than less unhappy ones at the task of being happy.

We should remind our readers that our studies were concerned with correlates of temperament, not correlates (or indeed causes) of immediate mood. In fact, as we noted in our earlier literature review, there is ample evidence suggesting that interventions designed to discourage rumination of distressing present or past circumstances can influence immediate mood (see Lyubomirsky \& Tkach, 2004, for a review) and, of course, therapists could attest to the fact that a decrease in such rumination can, in some cases, alleviate chronic depression as well. There is also evidence that immediate mood can be elevated by inducing individuals to savor positive present circumstances or recent past experiences and events, or by inducing them to contrast present circumstances with more difficult times in the past (Bryant, Smart, \& King, 2005; Emmons \& McCullough, 2003; Lyubomirsky, Dickerhoof, Boehm, \& Sheldon, 2008; Lyubomirsky, Sheldon, \& Schkade, 2005; Seligman, Rashid, \& Parks, 2006).

Less laboratory evidence exists on the effects on mood of inducing negative endowment or contrast-for example, telling people to think about personal losses or traumas, or about the changes in their physical abilities since their youth, although it is worth noting that successful negative mood inductions in the laboratory sometimes are accomplished by prompting participants to recall a loved one's death (see Laird \& Strout, 2007, for a review). In any case, we have little reason to doubt that such interventions can exert short-term effects on mood. The issue of greater theoretical and practical concern that remains to be answered is the capacity of chronic changes in ways of thinking about the past to produce sustained changes in happiness or, conversely, the capacity of sustained changes in happiness to produce changes in chronic ways of thinking about the past.

In examining our present results, we must pause to consider a possibility that would make the associations between temperament and endorsement of the endowment and contrast items in our questionnaire less interesting - that is, a tendency for happy and unhappy people to endorse items that are congruent with their respective general affective state and sense of well-being, and to reject items that are incongruent with those states. Least interesting of all is the possibility that if we have merely documented an individual difference in people's inclinations (irrespective of their actual affective states and the way they actually think about significant past events in their lives) to agree with statements about themselves that suggest positive states and commendable ways of looking at the world, and to disagree with statements about themselves that suggest negative states and noncommendable ways of looking at the world.

Fortunately, we can present at least some reassuring evidence in these regards. Although we do see an overall positivity bias both in response to the SHS and in endorsement of positive endowment and happiness-enhancing contrast items, there is ample reason to doubt that individual differences in response bias account for our correlational findings. In fact, it is the lack of a correlation between SHS responses and responses to some items describing seemingly commendable ways of reflecting on past events (i.e., enhancing happiness through contrast with difficult or unhappy times in the past) that casts doubt on the possibility that the other correlations we have reported are the product of a mere response bias. Notably, in Study 3, it was the intermediate group of "moderately" happy respondents who most consistently endorsed both types of contrast items. Nevertheless, in these studies, as in all studies that rely on self-report measures, especially self-report measures that might be seen as reflecting positively versus negatively on the self, the problem of response bias cannot be ignored.

\section{Final Thoughts on the Significance of the Present Studies}

We close this paper by returning to the observation that initially prompted us to investigate the role of memory, and ways of dealing with the past-namely, the observation of cases in which the expected, and often observed, association between life history and temperament does not seem to apply. Indeed, the impetus for our present investigation derived in part from the reflections of two Holocaust survivors of our acquaintance. One saw the events he had witnessed and the losses suffered in his youth as a source of everlasting sadness, and of the sentiment that present happiness would be shallow, even indecent. The other saw very similar events and experiences as a source of eternal contrast - as a reason to savor the joys of everyday life, and an admonition never to become angry or unhappy about trivial things. In other words, one acquaintance could not help endowing and ruminating about the horrors of his past; the other, while never forgetting that past, treated the contrast between past and present as a reason to be happy.

While individual differences of the sort we have explored may be a product less of strategy than of temperament, the messages people convey to one another can also exert an influence. Consider the endowment and contrast interpretations of the famous line from Casablanca with which we introduced this paper. By reconciling in Casablanca and hearing each other's account of their last fateful day in Paris (when Ilsa left Rick waiting alone in the train station rather than joining him in departing Paris), the two former lovers had made their affair in that most romantic of cities a potential source of enduring positive endowment for both of them. Still, the viewer of the film cannot help but wonder whether their memories of their days in Paris will nevertheless diminish the level of any future happiness that they may feel as they go through their lives and contrast positive relationships, no matter how positive, with that idyllic romance.

\section{References}

Affleck, G., \& Tennen, H. (1996). Construing benefits from adversity: Adaptational significance and dispositional underpinnings. Journal of Personality, 64, 899-922.

Affleck, G., Tennen, H., Urrows, S., Higgins, P., \& Abeles, M. (2000). Downward comparisons in daily life with chronic pain: Dynamic relations with pain and mood. Journal of Social and Clinical Psychology, 19, 499-518.

Bradburn, N. M. (1969). The structure of psychological well-being. Chicago: Aldine.

Brickman, P., Coates, D., \& Janoff-Bulman, R. (1978). Lottery winners and accident victims: Is happiness relative? Journal of Personality and Social Psychology, 36, 917-927.

Bryant, F. B. (1989). A four factor model of perceived control: Avoiding, coping, obtaining and savoring. Journal of Personality, 57, 773-797.

Bryant, F. B., Smart, C. M., \& King, S. P. (2005). Using the past to 
enhance the present: Boosting happiness through positive reminiscence. Journal of Happiness Studies, 6, 227-260.

Bryant, F. B., \& Veroff, J. (2006). Savoring: A new model of positive experience. Mahwah, NJ: Erlbaum.

Campbell, A., Converse, P. E., \& Rodgers, W. L. (1976). The quality of American life. New York: Sage.

Collins, R., Taylor, S., \& Skokan, L. (1990). A better world or a shattered vision? Changes in life perspectives following victimization. Social Cognition, 8, 263-285.

DeNeve, K. M., \& Cooper, H. (1998). The happy personality: A metaanalysis of 137 personality traits and subjective well-being. Psychological Bulletin, 124, 197-229.

Dermer, M., Cohen, M., Jacobsen, E., \& Anderson, E. (1979). Evaluative judgments of aspects of life as a function of vicarious exposure to hedonic extremes. Journal of Personality and Social Psychology, 37, 247-260.

Diener, E., \& Diener, C. (1996). Most people are happy. Psychological Science, 7, 181-185.

Diener, E., Emmons, R., Larsen, R., \& Griffin, S. (1985). The satisfaction with life scale. Journal of Personality Assessment, 49, 71-74.

Diener, E., Suh, E. M., Lucas, R. E., \& Smith, H. L. (1999). Subjective well-being: Three decades of progress. Psychological Bulletin, 125, 276-302.

Emmons, R. A., \& McCullough, M. E. (2003). Counting blessings versus burdens: An experimental investigation of gratitude and subjective wellbeing in daily life. Journal of Personality and Social Psychology, 84, 377-389.

Gable, S., Reis, H., Impett, E., \& Asher, E. (2004). What do you do when things go right? The intrapersonal and interpersonal benefits of sharing positive events. Journal of Personality and Social Psychology, 87, $228-245$.

Laird, J., \& Strout, S. (2007). Emotional behaviors as emotional stimuli. In J. A. Coan \& J. J. B. Allen (Eds.), Handbook of emotion elicitation and assessment. New York: Oxford University Press.

Langston, C. (1994). Capitalizing on and coping with daily-life events: Expressive responses to positive events. Journal of Personality and Social Psychology, 67, 1112-1125.

Lucas, R. E., Diener, E., \& Suh, E. (1996). Discriminant validity of well-being measures. Journal of Personality and Social Psychology, 71, $616-628$

Lyubomirsky, S., Dickerhoof, R., Boehm, J. K., \& Sheldon, K. M. (2008). How and why do positive activities work to boost well-being? An experimental longitudinal investigation of regularly practicing optimism and gratitude. Manuscript submitted for publication.

Lyubomirsky, S., Kasri, F., \& Zehm, K. (2003). Dysphoric rumination impairs concentration on academic tasks. Cognitive Therapy and Research, 27, 309-330.

Lyubomirsky, S., \& Lepper, H. (1999). A measure of subjective happiness: Preliminary reliability and construct validation. Social Indicators Research, 46, 137-155.

Lyubomirsky, S., \& Nolen-Hoeksema, S. (1995). Effects of self-focused rumination on negative thinking and interpersonal problem solving. Journal of Personality and Social Psychology, 69, 176-190.

Lyubomirsky, S., Sheldon, K. M., \& Schkade, D. (2005). Pursuing happi- ness: The architecture of sustainable change. Review of General Psychology, 9, 111-131.

Lyubomirsky, S., \& Tkach, C. (2004). The consequences of dysphoric rumination. In C. Papageorgiou \& A. Wells (Eds.), Rumination: Nature, theory, and treatment of negative thinking in depression (pp. 21-41). Chichester, England: Wiley.

Lyubomirsky, S., Tkach, C., \& DiMatteo, M. R. (2006). What are the differences between happiness and self-esteem? Social Indicators Research, 78, 363-404.

Lyubomirsky, S., \& Tucker, K. (1998). Implication of individual differences in subjective happiness for perceiving, interpreting, and thinking about life events. Motivation and Emotion, 22, 155-186.

Lyubomirsky, S., Tucker, K. L., \& Kasri, F. (2001). Responses to hedonically conflicting social comparisons: Comparing happy and unhappy people. European Journal of Social Psychology, 31, 511-535.

Markman, K., \& McMullen, M. (2003). A reflection and evaluation model of comparative thinking. Personality and Social Psychology Review, 3, 244-267.

Mussweiler, T. (2003). Comparison processes in social judgment: Mechanisms and consequences. Psychological Review, 110, 472-489.

Nolen-Hoeksema, S. (1991). Responses to depression and their effects on the duration of depressive episodes. Journal of Abnormal Psychology, $100,569-582$

Nolen-Hoeksema, S., Parker, L., \& Larson, J. (1994). Ruminative coping with depressed mood following loss. Journal of Personality and Social Psychology, 67, 92-104.

Scheier, M., \& Carver, C. (1985). Optimism, coping and health: Assessment and implications of generalized outcome expectancies. Health Psychology, 4, 219-247.

Schwarz, N., \& Bless, H. (1992). Constructing reality and its alternatives: An inclusion/exclusion model of assimilation and contrast effects in social judgment. In L. Martin \& A. Tesser (Eds.), The construction of social judgment (pp. 217-245). Hillsdale, NJ: Erlbaum.

Seidlitz, L., \& Diener, E. (1993). Memory for positive versus negative life events: Theories for the differences between happy and unhappy persons. Journal of Personality and Social Psychology, 64, 654-664.

Seligman, M. E. P., Rashid, T., \& Parks, A. C. (2006). Positive psychotherapy. American Psychology, 61, 774-788.

Stones, M. J., \& Kozma, A. (1986). "Happy are they who are happy ... ": A test between two causal models of happiness and its correlates. Experimental Aging Research, 12, 23-29.

Taylor, S., Wood, J., \& Lichtman, R. (1983). It could be worse: Selective evaluation as a response to victimization. Journal of Social Issues, 39, $19-40$.

Tversky, A., \& Griffin, D. (1991). Endowment and contrast in judgments of well-being. In F. Strack, M. Argyle, \& N. Schwarz (Eds.), Subjective well-being: An interdisciplinary perspective (pp. 101-118). Elmsford, NY: Pergamon Press.

Watson, D., Clark, L. A., \& Tellegen, A. (1988). Development and validation of brief measures of positive and negative affect: The PANAS scales. Journal of Personality and Social Psychology, 54, 1063-1070.

Received July 7, 2008

Revision received June 1, 2009 Accepted June 1, 2009 